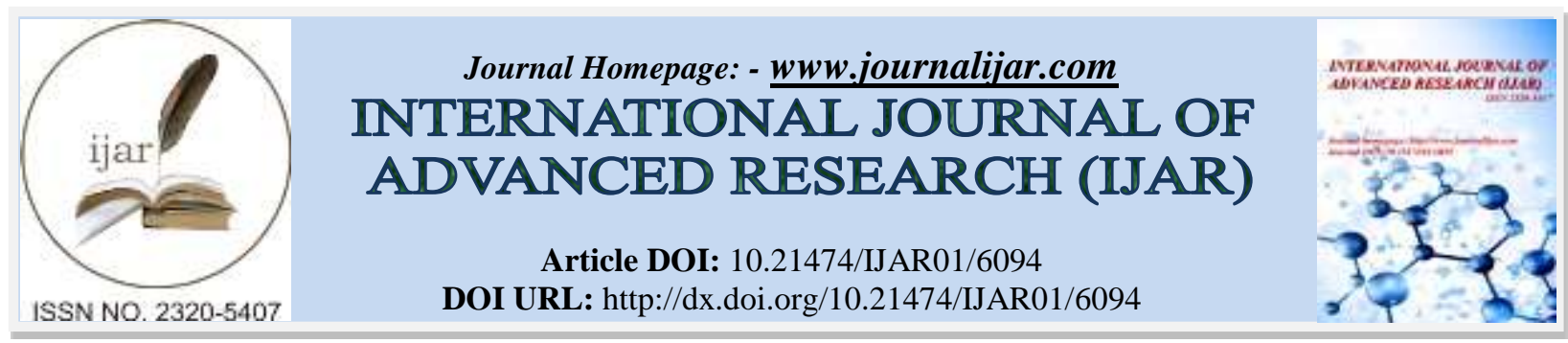

RESEARCH ARTICLE

\title{
GAME THEORY MODEL OF CONSUMERS' RESPONSE TO MOBILE TELECOMMUNICATION SERVICE OFFERS. A CASE STUDY OF MOTENS AND VODAG IN THE TAMALE METROPOLIS IN GHANA.
}

Kwaku Darkwah ${ }^{1}$ and Bashiru Abubakari ${ }^{2}$.

1. Department of Mathematics, College of Science, Kwame Nkrumah University of Science and Technology, Kumasi - Ghana.

2. Department of Mathematics, E. P. College of Education, Bimbilla - Ghana.

\section{Manuscript Info}

(.........................

Manuscript History

Received: 18 October 2017

Final Accepted: 18 November 2017

Published: December 2017

\section{Key words:-}

Game Theory, Strategies, Payoffs, Nash Equilibrium, Algorithm, Consumers, Service Offers, Lemke-Howson Algorithm, Polytope, Tableaux.

\section{Abstract}

Telecommunication and mobile phone usage for that matter have assumed a centre stage in the Ghanaian economy to an extent that its possession has become a necessity. The situation resulted to serious competition among Service Providers in the sector in their quest to control the market. The aims of this study are to model consumers' response to the service offers employed by two Mobile Service Operators in the Ghanaian market using game theory as well as to determine the optimal strategies and utilities of the considered firms. These firms included Motens and Vodag. We compared the companies selected service offers to determine how consumers react to such offers. The Lemke-Howson Algorithm was used to solve the model and Nash Equilibria of the game were determined. The optimal strategies and utilities of the competing firms were determined. It is recommended that the company with less market share should re-engineer its service offers for increased share of the market.

Copy Right, IJAR, 2017,. All rights reserved.

\section{Introduction:-}

Understanding the relevance and contribution of the service offers employed by Mobile Service Providers is essential for both mobile users and service providers. Service Offers are the special packages employed by Mobile Service Providers to motivate consumers to patronize their products. Because of market competition, the service providers employ the offers in order to gain control of the market. These offers most often provide some call charge discounts or bonuses to consumers for in their usage. As a result, almost every mobile phone user of the Ghanaian market either register for one form of offer or the other. However, it is unknown as to which of the offers are influencing consumers' patronage.

In this paper, we study competition between two firms in the Ghana's mobile telecommunication industry who employ various forms of service offers to lure consumers in the market. We approach the study by viewing the market as a game, and studying its Nash-equilibria. The main goals of this study are to determine the optimal strategies and utilities for the two competing firms using a game theory model. The service offers employed are regarded as strategies in order to use game theory for analysis. 
Many authors have applied game theory in diverse areas. Zeng and Fan (2005) applied the 'Prisoner's Dilemma model of game theory to determine the levels of competition and cooperation between operators in the China's Telecommunication Industry. The researchers used the model's payoff scenarios to determine the equilibrium point of the competition in the market. Musa and Sunday (2008) employed principles of game theory to determine optimal strategies for two competing banks to open their branches in a city within two business locations. The authors to determine the optimal strategies for the banks used the Minimax (Maxmin) Criterion. Sanjeev and Michael (2012) also studied competition between two firms denoted by Red and Blue who used their resources to maximize products adoption by consumers located in a social network. Manish et al (2008) modeled Los Angeles Airport Security situation using the Bayesian Stackelberg game. In solving the model the researchers developed a software assistant agent called Assistant for Randomized Monitoring over Routes (ARMOR) to aid police or other security agencies in randomizing their security schedules in the airport. There are also recent stream of literature in game theory that study issues related to marketing strategies over the social networks. Ozan et al. (2011) studied the optimal strategies of a monopolist selling a divisible good (service) to consumers that are embedded in a social network. They considered a two-stage pricing-consumption game to model the interaction between the agents (consumers) and the monopolist. Rafael et al. (2012) carried out a research on the quality of consumer service provided by Mobile telecommunication operators in the market. The study, primarily, aimed at determining whether consumers of mobile telecommunications are subject to abuses by the service providers. Oziegbe (2011) applied game theory in solving business decision problems in undeveloped countries. He used Nigeria as a case study. The researcher used the Minimax (Maximin) Criterion to determine the saddle point of the pure strategy game. Alex (2013) studied the effects of entry by additional seller(s) or buyer(s) into a model of oligopoly market, in which there is bilateral relationship (cooperation) between sellers and buyers. It is assumed that the firms produced homogeneous goods.

\section{Related Works:-}

Various researchers used varied algorithms to solve linear programming formulations. Boah et al. (2014) applied the two-person constant-sum game of game theory to analyze the levels of patronage of two competing Radio Stations in Kumasi. They identified the two stations' common programmes and used them as the strategies of the stations for the game. The authors to determine the firms' optimal strategies used the Minimax (Maxmini) Criterion. Yusuf et al. (2014), on the other hand, used Two-Person Zero-Sum Game to determine the level of competition between the tanners and 'pomo' wholesalers in hides marketing competition in Nigeria. The researchers adopted the Minimax (Maxmin) Criterion as a solution method for the game to determine the equilibrium point. Achugamonu et al. (2012) for instance carried out an investigation on project optimization of two computing firms in advertising their products and other services they render within Nigeria. They formulated linear programming model of game theory to determine an optimal resource allocation of both firms. The difference of their work to ours is that they adopted the Simplex Method and Duality Theory as their solution methods to obtain an optimum benefit for the twotelecom firms. Alexophoulos (2013) modeled a game into linear programming and used Simplex Algorithm to determine optimal strategies of the game. Abd El-Kareem (2013) carried out a comparative study between linear and graphical methods in solving optimization problems. She observed that even though both approaches are used in solving game theory models, the graphical solutions are only applicable to games in which at least one of the players has two strategies only. The limitation of this approach is that it is not feasible for games with larger matrices. Abdu-Majeed (2011) also formulated a linear programming model of game theory to study consumers' response to service offers of the two leading telephone networks in Ghana. He employed the Primal-Dual Interior Point Method based on the Mehrotra's Predictor-Corrector Algorithm to obtain optimal strategies at Nash Equilibrium for the firms. In our work, we used the Lemke-Howson Algorithm to solve the linear programing model we formulated. It is observed that the advantage of the L-H Algorithm over the Simplex is running time. The L-H Algorithm takes lesser time to solve the model than the Simplex Algorithm. The Simplex is observed to have an exponential running time with larger matrices. The other advantage of the L-H Algorithm over the Simplex is that the former is used in solving bimatrix data.

\section{Methods:- \\ Linear Programming Formulation of Two-Person Zero-Sum Games:-}

In a perfect Zero-Sum Game of pure strategies there exist a Nash Equilibrium, which determines the optimal strategy for each player as the intersection of two computing payoff strategy.

In a game of mixed strategies, the maximin criterion provides the equilibrium solution. The maximin criterion induces the linear programming formulation. It stipulates that player A selects the mixed strategy that maximizes the 
minimum expected payoff to him. Equivalently, the player B also selects the mixed strategy that minimizes the maximum expected loss to him. The average payoff of the game when both players use their optimal strategies is denoted by V. The game of two-person zero-sum exhibits the primal-dual relationship as in linear programming. When the players simultaneously use their optimal strategies, the winner expected gain is equal to the loser expected loss, (Hamdy, 2007).

The Minimax Theorem: If mixed strategies are allowed, the pair of mixed strategies that is optimal according to the minimax criterion provides a stablelequilibrium solution (the value of the game, V), so that neither player can do better by unilaterally changing his/her strategy, (Hillier \& Liebermann, 2001).

Consider the following:

If Player A's optimal strategies $x_{1}, x_{2}, x_{3} \cdots, x_{m}$ satisfy the maximin criterion then we have the formulation:

$$
\begin{gathered}
\text { Minimize } V=X_{1}+X_{2}+X_{3}+\cdots+X_{m} \\
\text { Subject to the Payoff Constraints: } \\
a_{11} X_{1}+a_{21} X_{2}+a_{31} X_{3}+\cdots+a_{m 1} X_{m} \geq 1 \\
a_{12} X_{1}+a_{22} X_{2}+a_{32} X_{3}+\cdots+a_{m 2} X_{m} \geq 1 \\
a_{13} X_{1}+a_{23} X_{2}+a_{33} X_{3}+\cdots+a_{m 3} X_{m} \geq 1 \\
\vdots \\
a_{1 n} X_{1}+a_{2 n} X_{2}+a_{3 n} X_{3}+\cdots+a_{m n} X_{m} \geq 1 \\
X_{i}=\frac{x_{i}}{V}, x_{i} \geq 0, \text { fori }=1,2,3, \cdots, m
\end{gathered}
$$

Player B's optimal strategies $y_{1}, y_{2}, y_{3}, \cdots y_{n}$ are determined by solving the formulation:

$$
\begin{gathered}
\text { Maximize } V=Y_{1}+Y_{2}+Y_{3}+\cdots+Y_{n} \\
\text { Subject to the constraints } \\
a_{11} Y_{1}+a_{12} Y_{2}+a_{13} Y_{3}+\cdots+a_{1 n} Y_{n} \leq 1 \\
a_{21} Y_{1}+a_{22} Y_{2}+a_{23} Y_{3}+\cdots+a_{2 n} Y_{n} \leq 1 \\
a_{31} Y_{1}+a_{32} Y_{2}+a_{33} Y_{3}+\cdots+a_{3 n} Y_{n} \leq 1 \\
\vdots \\
a_{m 1} Y_{1}+a_{m 2} Y_{2}+a_{m 3} Y_{3}+\cdots+a_{m n} Y_{n} \leq 1 \\
Y_{j}=\frac{y_{j}}{V}, y_{j} \geq 0, \text { for } \quad j=1,2,3, \cdots, n
\end{gathered}
$$


The Solution Method: Lemke-Howson Algorithm:-

According to David (2011), von Stengel (2002) and Amin (2009), the Lemke-Howson (L-H) algorithm considers a two-person bi-matrix game the payoff matrices are $A_{m x n}$ and $B_{m x n}$. A pair of strategies $(x, y)$ is a Nash Equilibrium if and only if:

$$
\begin{aligned}
& \forall i, 1 \leq i \leq m, x_{i}>0 \Rightarrow A_{k j} y_{j}=\max \sum_{j=m+1}^{m+n}\left(A_{i j} y_{j}\right) \\
& \forall j, m+1 \leq j \leq m+n, y_{j}>0 \Rightarrow x_{i}^{T} B_{i k}=\max \sum_{i=1}^{m}\left(x_{i}^{T} B_{i j}\right)
\end{aligned}
$$

The assumption is that: All entries of A and B are non-negatives that, A has no all-zero columns and B has no allzero rows.

If $x$ and $y$ are the strategies of players A and B then the support $S$ of a mixed strategy is the set of indices $i$ and $j$ of pure strategies $x_{i}$ and $y_{j}$ that have positive probabilities. Thus

$$
S(x)=\left\{i \mid x_{i}>0\right\} \text { and } S(y)=\left\{j \mid y_{j}>0\right\} \text {. }
$$

The description of the algorithm and the demonstration of Nash's theorem for two-person bi-matrix games rely on two polytopes (feasible regions) for Linear Program (LP).

Let $\mathrm{Bj}$ denote the column of $\mathrm{B}$ corresponding to index $j$ and let $\mathrm{A}^{\mathrm{i}}$ denote the row of A corresponding to index $i$. The polytopes $(\mathrm{P})$ are:

$$
\begin{aligned}
& P_{1}=\left\{x \in \mathfrak{R}^{M} \mid\left(\forall i \in M: x_{i} \geq 0\right) \text { and }\left(\forall j \in N: x^{T} B_{j} \leq 1\right)\right\} \\
& P_{2}=\left\{y \in \mathfrak{R}^{N} \mid\left(\forall j \in N: y_{j} \geq 0\right) \text { and }\left(\forall i \in M: A^{i} y \leq 1\right)\right\}
\end{aligned}
$$

We note that $\mathrm{A}$ and $\mathrm{B}$ are $m \times n$ matrices.

The inequalities that define $\boldsymbol{P}_{1}$ have the following meaning:

- $\quad$ If $x \in P_{1} \quad$ is strictly $x_{i}>0$ and $x^{T} B_{j}=1$

Then the jth column of $\mathrm{B}$ is the best response strategy to the normalized $x$ belonging to $P_{1}$ Similarly,

If $y \in P_{2}$ is strictly $\mathrm{y}_{j}>0$ and $A^{i} y=1$

then the $i$ th row of $\mathrm{A}$ is the best response strategy to the normalized $y$ belonging to $P_{2}$

In the process of using the Lemke-Howson algorithm the vector solutions $\mathrm{x}$ and $\mathrm{y}$ obtained are not proper solution to the mixed strategy game until they are normalized into stochastic vectors. Thus

normalised $(x):=x /\left(\sum_{i} x_{i}\right)=\left(\sum_{i} x_{i}\right)^{-1} x$ and 
normalised $(y):=y /\left(\sum_{j} y_{j}\right)=\left(\sum_{j} y_{j}\right)^{-1} y$

The Lemke-Howson Algorithm Steps:-

In Lemke-Howson Algorithm, the following steps are used:

Step 1: Enter player A and player B matrices as A and B.

Step 2: Create system of equations matrix for A as $r=1-A y$

and for B as $s=1-B^{T} x$

where $\mathrm{r}$ and $s$ are slack variables

Step 3: Choose a pivot variable from either system of equations (1) or (2).

Step 4: Select a basis by using system of equations (1) or (2). Suppose $x_{i}$ component of $\mathrm{x}$ in system (2) is chosen as basis (or entering variable) to be made subject of equation, then check system (2) to see which row (say row $j$ ) has lowest coefficient of $x_{i}$. Row $j$ becomes the pivot row. Ties are broken arbitrary. Make $x_{i}$ the subject of row $j$ in system (2) and the slack variable $r_{i}$ becomes the leaving variable. Use row $j$ to eliminate all $x_{i}$ in all other rows of system (2).

Step 5: Once $r_{i}$ is leaving variable in system (2) $y_{j}$ becomes entering variable in system (1).

Step 4 is then repeated until the left-hand side of systems (1) and (2) respectively has components of $\mathrm{y}$ and $\mathrm{x}$ as subjects and the right-hand sides are of constants and slack variables only.

Step 6: The solution is obtained by setting all the slack variables to zeros and normalizing the results.

\section{Problem Statement:-}

There are five (5) mobile service providers currently in the Ghanaian market. They include the Motens, Vodag, Arigo, Epeso, and Gilog. Those selected for this exercise are the Motens and the Vodag. The selection was based on firms with highest market shares in the Telecom Industry. The Motens is leading the market with $45.86 \%$ shares followed by Vodag with $22.65 \%$. These two firms alone control about $69 \%$ of the market.

This study was conducted in Tamale Metropolis in Ghana. It has a population of 371,351. The target for the study was the literate population in the metropolis, which constituted $60.1 \%$ of the entire Tamale population, GSS (2010). Quota and Purposeful Sampling techniques were used to obtain a data for the study. The quota sampling technique was used to categorize the service users in order to obtain an all-inclusive sample for the study. The purposeful sampling technique was used to select 200 customers who use both the Motens and Vodag networks. Structured questionnaire was used to obtain information from the sample of 200 respondents who are subscribers to the two competing mobile phone service providers. The data depicts consumers' preference for service offers advertised by the two competing firms. In all, eight (8) relevant services offers were selected for each telecom company. The selection of the offers was influenced by the following criteria: (1) the offers that were frequently advertised in the electronic media, (2) the offers that were targeting all categories of customers of the respective firms and (3) the level of awareness of the firms' services offers by the customers. The number of respondents choosing a particular service offer from a service provider was recorded as a gain or payoff for that service provider. The selected service offers and the data obtained are presented in Table 1, Table 2 and Table 3 below:

Table 1:- Service Offers of Motens -Ghana

\begin{tabular}{|l|l|l|l|l|l|l|l|l|}
\hline Service & $\begin{array}{l}\text { Zonal } \\
\text { Calls }\end{array}$ & $\begin{array}{l}\text { Family } \\
\& \\
\text { Friends }\end{array}$ & $\begin{array}{l}\text { Conference } \\
\text { Calls }\end{array}$ & $\begin{array}{l}\text { Extra } \\
\text { Time }\end{array}$ & $\begin{array}{l}\text { Free } \\
\text { Beyond } \\
\text { One }\end{array}$ & $\begin{array}{l}\text { Mobile } \\
\text { Money }\end{array}$ & $\begin{array}{l}\text { Sunday } \\
\text { Special }\end{array}$ & Pay4Me \\
\hline Label & $\mathrm{X}_{1}$ & $\mathrm{X}_{2}$ & $\mathrm{X}_{3}$ & $\mathrm{X}_{4}$ & $\mathrm{X}_{5}$ & $\mathrm{X}_{6}$ & $\mathrm{X}_{7}$ & $\mathrm{X}_{8}$ \\
\hline
\end{tabular}


Table 2:- Service Offers of Vodag-Ghana

\begin{tabular}{|l|l|l|l|l|l|l|l|l|}
\hline Service & $\begin{array}{l}\text { Red } \\
\text { Classic }\end{array}$ & $\begin{array}{l}\text { Double } \\
\text { Value } \\
\text { Monthly }\end{array}$ & $\begin{array}{l}\text { Supreme } \\
\text { Value }\end{array}$ & $\begin{array}{l}\text { Double } \\
\text { Value } \\
\text { Daily }\end{array}$ & $\begin{array}{l}\text { Red } \\
\text { Rush }\end{array}$ & $\begin{array}{l}\text { Supreme } \\
\text { Lite }\end{array}$ & Flat Rate & Red Hott \\
\hline Label & $\mathrm{Y}_{1}$ & $\mathrm{Y}_{2}$ & $\mathrm{Y}_{3}$ & $\mathrm{Y}_{4}$ & $\mathrm{Y}_{5}$ & $\mathrm{Y}_{6}$ & $\mathrm{Y}_{7}$ & $\mathrm{Y}_{8}$ \\
\hline
\end{tabular}

Table 3:- Pairwise Payoffs of Motens -Ghana and Vodag-Ghana

\begin{tabular}{|c|c|c|c|c|c|c|c|c|}
\hline $\begin{array}{l}\text { B } \\
\text { A }\end{array}$ & $Y_{9}$ & $Y_{10}$ & $Y_{11}$ & $Y_{12}$ & $\mathbf{Y}_{13}$ & $Y_{14}$ & $Y_{15}$ & $Y_{16}$ \\
\hline$\overline{X_{1}}$ & $(124,76)$ & $(56,144)$ & $(61,139)$ & $(68,132)$ & $(117,83)$ & $(75,125)$ & $(98,102)$ & $(125,75)$ \\
\hline $\mathbf{X}_{2}$ & $(126,74)$ & $(62,138)$ & $(63,137)$ & $(72,128)$ & $(\mathbf{1 1 5 , 8 5 )}$ & $(89,111)$ & $(98,102)$ & $(122,78)$ \\
\hline $\mathbf{X}_{3}$ & $(129,71)$ & $(78,122)$ & $(68,132)$ & $(69,131)$ & $(95,105)$ & $(83,117)$ & $(92,102)$ & $(111,89)$ \\
\hline $\mathbf{X}_{4}$ & $(112,88)$ & $(65,135)$ & $(67,133)$ & $(63,137)$ & $(102,98)$ & $(78,122)$ & $(97,103)$ & $(111,89)$ \\
\hline$X_{5}$ & $(118,82)$ & $(72,128)$ & $(128,72)$ & $(74,126)$ & $(108,92)$ & $(85,115)$ & $(100,100)$ & $(119,81)$ \\
\hline$X_{6}$ & $(148,52)$ & $(137,63)$ & $(122,78)$ & $(131,69)$ & $(156,44)$ & $(144,56)$ & $(150,50)$ & $(157,43)$ \\
\hline $\mathbf{X}_{7}$ & $(124,76)$ & $(94,106)$ & $(79,121)$ & $(88,112)$ & $(72,128)$ & $(101,99)$ & $(114,86)$ & $(137,63)$ \\
\hline $\mathbf{X}_{8}$ & $(94,106)$ & $(74,126)$ & $(73,127)$ & $(74,126)$ & $(98,102)$ & $(86,114)$ & $(95,105)$ & $(97,103)$ \\
\hline
\end{tabular}

The entries of cells have a constant sum of 200 , which is equal to the total number of respondents. Motens has the first pay-off entry while Vodag has the second pay-off entry in the ordered pairs.

\section{Computational Procedure:-}

The pay-off matrix data of Table 3 were separated to get matrix A for Motens and matrix B for Vodag. The bimatrix A and B and used as input data for a modified Lemke-Howson Algorithm code of (Richard, 2014). and solved on the MATLAB platform. The computer used to perform this analysis was HP (WELCOME PC) with Processor: Intel(R) Celeron(R) CPU B815 @ 3.2 GHz, RAM: 4.00 GB and 32-bit Operating System.

The code was run ten consecutive times to obtain the results. The same results were obtained in each run. The bimatrix A and B are at the appendix.

\section{Results:-}

The results of the game are summarized in Tables 4 and 5

Results for Motens-Ghana:-

Table 4 contains payoffs, which are gains for Motens and losses for Vodag. It also contains the probabilities with which both the row and column (Vodag) players have to use simultaneously and the possible values of the game (V) are indicated in the last row and column entries.

Table 4:- Nash Equilibrium Table for Motens-Ghana

\begin{tabular}{|l|l|l|l|l|l|l|l|l|l|}
\hline MOTENS & $\mathbf{0}$ & $\mathbf{0}$ & $19 / 21$ & $2 / 21$ & $\mathbf{0}$ & $\mathbf{0}$ & $\mathbf{0}$ & $\mathbf{0}$ & $\sum_{j=m+1}^{m+n}\left(a_{i j} y_{j}\right)$ \\
\hline $\mathbf{0}$ & & & & & & & & & $\mathbf{6 1 . 6 7}$ \\
\hline $\mathbf{0}$ & 124 & 56 & 61 & 68 & 117 & 75 & 98 & 125 & $\mathbf{6 3}$ \\
\hline $\mathbf{0}$ & 126 & 62 & 63 & 72 & 115 & 89 & 98 & 122 & $\mathbf{6 3 . 8 7}$ \\
\hline $\mathbf{1} / 7$ & 129 & 78 & 68 & 69 & 95 & 83 & 92 & 111 & $\mathbf{6 8 . 1 0}$ \\
\hline $\mathbf{6} / 7$ & 112 & 65 & 67 & 63 & 102 & 78 & 97 & 111 & 66.62 \\
\hline $\mathbf{0}$ & 118 & 72 & 128 & 74 & 108 & 85 & 100 & 119 & $\mathbf{7 2 . 1 9}$ \\
\hline $\mathbf{0}$ & 148 & 137 & 122 & 131 & 156 & 144 & 150 & 157 & $\mathbf{1 2 2 . 8 6}$ \\
\hline
\end{tabular}




\begin{tabular}{|l|l|l|l|l|l|l|l|l|l|}
\hline$\sum_{i=1}^{m}\left(a_{i j} x_{i}\right)$ & 143.71 & 127.71 & 122.86 & 112.86 & 149.14 & 135.57 & 142.86 & 151.57 & \\
\hline
\end{tabular}

Note: The arrow indicates the approximated value of the game $\mathrm{V}=122.86$

The value of the game $(\mathrm{V})$ is the maximum value of the row sums. It indicates a maximum gain for Motens-Ghana and minimum losses for Vodag-Ghana. Below is the calculation:

$$
\begin{aligned}
& V=\max \sum_{j=m+1}^{m+n} A_{i j} y_{j}, \\
& \mathrm{~V}=\left\{(148)(0)+(137)(0)+(122)\left(\frac{19}{21}\right)+(131)\left(\frac{2}{21}\right)+(156)(0)+(144)(0)+(150)(0)+(157)(0)\right\} \\
& V=\{\mathrm{O}+\mathrm{O}+110.38095+12.47619+\mathrm{O}+\mathrm{O}+\mathrm{O}+\mathrm{O}\} \\
& V=122.85714 \\
& V=122.86 \\
& \left\{x_{1}=\mathrm{O}, x_{2}=\mathrm{O}, x_{3}=\mathrm{O}, x_{4}=\mathrm{O}, x_{5}=1 / 7, x_{6}=6 / 7, x_{7}=\mathrm{O}, x_{8}=\mathrm{O}\right\}
\end{aligned}
$$

\begin{tabular}{|c|c|c|c|c|c|c|c|c|c|}
\hline VODAG & 0 & $\mathbf{0}$ & $\mathbf{0}$ & 0 & $1 / 7$ & $6 / 7$ & $\mathbf{0}$ & $\mathbf{0}$ & $\sum_{j=m+1}^{m+n} b_{i j} x_{i}$ \\
\hline $\mathbf{0}$ & 76 & 74 & 71 & 88 & 82 & 52 & 76 & 106 & 56.29 \\
\hline $\mathbf{0}$ & 144 & 138 & 122 & 135 & 128 & 63 & 106 & 126 & 72.29 \\
\hline $19 / 21$ & 139 & 137 & 132 & 133 & 72 & 78 & 121 & 127 & $\begin{array}{l}77.143 \\
\text { 个 }\end{array}$ \\
\hline $2 /$ & 132 & 128 & 131 & 137 & 126 & 69 & 112 & 126 & 77.14 \\
\hline 0 & 83 & 85 & 105 & 98 & 92 & 44 & 128 & 102 & 50.86 \\
\hline $\mathbf{0}$ & 125 & 111 & 117 & 122 & 115 & 56 & 99 & 114 & 64.43 \\
\hline $\mathbf{0}$ & 102 & 102 & 108 & 103 & 100 & 50 & 86 & 105 & 57.14 \\
\hline $\mathbf{0}$ & 75 & 78 & 89 & 89 & 81 & 43 & 63 & 103 & 48.43 \\
\hline$\sum^{m} h$ & 138.33 & 136.14 & 131.90 & 133.38 & 77.14 & 77.14 & 120.14 & 126.90 & \\
\hline
\end{tabular}

and the Value of the game for Motens was $V=\mathbf{1 2 2 . 8 6}$.

\section{Results for Vodag-Ghana:-}

Table 5 below contains payoffs, which are gains for Vodag and losses for Motens. It also contains the probabilities with which both the row and column players have to use respectively. The possible values of the game (V) are also indicated.

Table 5B:- Nash Equilibrium Table for Vodag-Ghana

Note: The arrow indicates the approximated value of the game $V=77.143$

The value of the game $(\mathrm{V})$ is the maximum value of the row sums. It indicates a maximum gain for Vodag and a maximum loss for Motens. Below is the calculation: 


$$
\begin{gathered}
V=\max \sum_{j=m+1}^{m+n} B_{i j} x_{i} \\
V=\{(139)(0)+(137)(0)+(132)(0)+(133)(0)+(72)(1 / 7)+(78)(6 / 7)+(121)(0)+(127)(0)\} \\
V=\{0+0+0+0+10.2857+66.8571+0+0\} \\
V=77.14284286 \\
V=77.143
\end{gathered}
$$

The results obtained as optimal solution for Vodag.

$$
\left\{y_{1}=0, y_{2}=0, y_{3}=19 / 21, y_{4}=2 / 21, y_{5}=0, y_{6}=0, y_{7}=0, y_{8}=0\right\}
$$

The value of the game $V=\mathbf{7 7 . 1 4 2 9}$.

\section{Discussions:-}

The results obtained indicate that the optimal mixed strategies for Motens are

$$
\left\{x_{1}=0, x_{2}=0, x_{3}=0, x_{4}=0, x_{5}=1 / 7, x_{6}=6 / 7, x_{7}=0, x_{8}=0\right\}
$$

and the value of the game $\mathbf{V}=\mathbf{1 2 2 . 8 5 7 1}$.

This means that Motens will have to adopt its pure strategies with the following probabilities: Free Beyond One $=$ 0.1429 and Mobile Money $=0.8571$. The rest, which included Zonal Calls, Family \& Friends, Conference Calls, Extra Time, Sunday Special and Pay4Me, have zero probabilities. This is to ensure an expected gain of 123 customers out of the 200 mobile phone users in the study from Tamale.

The interpretation of the results is that the Motens must pursue the strategy Mobile Money more as it outperformed all the other strategies, followed by the strategy Free Beyond One. The services with zero probabilities do not contribute to the value of the game.

The results obtained indicate that the optimal mixed strategies for Vodag are

$$
\left\{y_{1}=0, y_{2}=0, y_{3}=19 / 21, y_{4}=2 / 21, y_{5}=0, y_{6}=0, y_{7}=0, y_{8}=0\right\}
$$

and the value of the game $\mathbf{V}=\mathbf{7 7 . 1 4 2 9}$.

This means that the Vodag must adopt its pure strategies with the following probabilities: Supreme Value $=0.9048$ and Double Value Daily $=0.0952$, since the rest have zero probabilities. This ensures an expected gain of 77 customers.

The interpretation of the results is that the Vodag must pursue the strategy Supreme Value more as it overshadowed all the other strategies, followed by its strategy Double Value Daily. The services with zero probabilities do not contribute to the value of the game.

The results further indicated that neither of the companies have a chance of increasing its gains by changing its strategies unilaterally or with the other maintaining its equilibrium strategies of the game. This is a clear testimony of the Minimax Theorem of (Hillier \& Liebermann, 2001).

\section{Conclusion:-}

In this work, two linear programming models were formulated to find optimal strategies at equilibrium for two most popular telecom companies operating in Ghana. The Lemke-Howson Algorithm, the solution method was used, 
found the optimal strategies. The optimal strategies obtained for Motens are Mobile Money and Free Beyond One whereas that of Vodag are Supreme Value and Double Value Daily. It was realized at equilibrium that, Motens will gain an expected payoff 123 representing 61\% and Vodag will gain an expected payoff of 77 representing 39\% out of the 200 respondents used in the study. This means that Motens will gain 123 customers and lose 77 customers whereas Vodag will lose 123 customers and gain 77 customers. Vodag will need to re-engineer its service offers to be more competitive in order to attract meaningful customers so as to increase its market share..

\section{References:-}

1. Abd El-Kareem, M. M. (2013). Comparative Study between Linear and Graphical Methods in Solving Optimization Problems. IAENG International Journal of Computer Science, 37:1, IJCS_37_1_13.

2. Achugamonu, P. C., Inyama, S. C. and Onuoha, D. C. (2012) Application of Game Theory in Objective Project Optimization for Nigerian Telecommunication Industry. West African Journal of Industrial \& Academic Research. ISSN: 1116-5405, 2(1), pp. 62 - 69. (http://www.wajiaredu. Com). (09/03/2015).

3. Alex, D. (2013). The Effects of Entry in Bilateral Oligopoly. Games ISSN 2073 - 4336, 4, pp. 283 - 303. Published online in Open Access Game (http://www.mdpi.com/Journal/Games). (Accessed on 01/12/2014).

4. Amin, S. (2009). Computation of Equilibria: Lemke-Howson Algorithm. Stanford University. http://web.stanford.edu/ saberi/lecture4.pdf. pp. 1 - 3. (Accessed on 12/01/2015).

5. Abdu-Majeed (2011). Mathematical Model of Consumers Response to Service Offers: Thesis, KNUST, Kumasi - Ghana.

6. Boah, D. K., Twum, S. B. and Amponsah, S. K. (2014). Patronage of Two-Radio Station in Kumasi. Journal of Innovative Technology and Education, 1, pp. 17 - 23. (Accessed on 26/11/2014).

7. David, P. (2011). Game Theory and Algorithms: The Lemke-Howson Algorithm, EPFL, Lausanne. (http://ints.io/daveagp/gta/lecture6.pdf). pp. 1 - 8, (10/02/2015).

8. Ghana Statistical Service: 2010 PHC, 2013 update, http://www.statsghana.gov.gh 20/02/15.

9. Hamdy, T. A. (2007). Operations Research: An Introduction (8th ed.). Pearson Education Inc, U.S.A. pp. 520 530. (Accessed on11/11/2014).

10. Hillier, F. S. and Lieberman, G. J. (2001). Introduction to Operations Research, (7th ed.), McGraw-Hill. New York. pp. 726 - 748. (Accessed on 17/02/2015).

11. James, P. et al. (2008). Using Game Theory for Los Angeles Airport Security. Sigecom Exchanges: Teamcore Research Group, University of Southern California.

12. Musa, D. S. and Sunday, A. R. (2008). Optimum Gain Analysis Using the Principles of Game Theory. Leonardo Journal of Science, ISSN 1583-0233, pp. 1 - 6. (Accessed on 26/11/2014).

13. Ozan, C., Kostas, B. and Asuman, O. (2011). Optimal Pricing in Networks with Externalities. (http://arxiv.org/pdf/1101.5617v1 [cs.GT]). pp. 1 - 29. (16/11/2014).

14. Oziegbe, A. (2011). Application of Game Theory to Business Strategy in Undeveloped Countries: A Case for Nigeria. Journal of Social Sciences, 27(1), pp. 1 - 5. (Accessed on 09/03/2015).

15. Rafael, L. Z., Tiodosio, P., Teresa, G. and Covadonga, G. T. (2012). Customer Service Quality and Incomplete Information in Mobile Telecommunications: A Game Theoretical Approach to Consumer Protection. Social Science Research Network (SSRN): http://ssrn.com. (Accessed on 18/10/2014).

16. Sanjeev, G. and Michael, K. (2012). Competitive Contagion in Network. http://arxiv.org/pdf/1110.6372v3 [cs.GT]. pp. 1 - 16. (Accessed on 16/11/2014).

17. Von Stengel, B. (2002). Computing Equilibria for Two-Person Games. Handbook of Game Theory with Economic Applications, Vol. 3, pp. 1723 - 1759. (10/10/2014).

18. Yusuf, O., Sanni, S. A. and Akpoko, J. G. (2014). Game Theory: An Application to Tanners and 'Pomo' Wholesalers in Hides Marketing Competition in Nigeria. British Journal of Economics, Management \& Trade, 5(2): 147-152, ISSN: 2278-098X. (http:// www.sciencedomain.org). (Accessed on 10/03/2015).

19. Zeng, J. and Fan, H. (2005). China's Telecommunications Market and Game Theory. Beijing University of Posts and Telecommunications. pp.1 - 10. http://www.i-teletraffic.org/fileadmin/ITCBibDatabase. (Accessed on 18/10/2014).

20. Richard K. (2014). Lemke-Howson Algorithm for 2-Player Games: MathWorks. (http://www.mathworks.com/matlabcentral/... /44279-lemke-howson). (12/02/15). 
APPENDIX I

Table A1: Payoff Table for Motens -Ghana

\begin{tabular}{|c|c|c|c|c|c|c|c|c|}
\hline MOTENS & $\mathbf{Y}_{9}$ & $\mathbf{Y}_{10}$ & $\mathbf{Y}_{11}$ & $\mathbf{Y}_{12}$ & $\mathbf{Y}_{13}$ & $\mathbf{Y}_{14}$ & $\mathbf{Y}_{15}$ & $Y_{16}$ \\
\hline $\mathbf{X}_{1}$ & 124 & 56 & 61 & 68 & 117 & 75 & 98 & 125 \\
\hline $\mathbf{X}_{2}$ & 126 & 62 & 63 & 72 & 115 & 89 & 98 & 122 \\
\hline $\mathbf{X}_{\mathbf{3}}$ & 129 & 78 & 68 & 69 & 95 & 83 & 92 & 111 \\
\hline$X_{4}$ & 112 & 65 & 67 & 63 & 102 & 78 & 97 & 111 \\
\hline $\mathbf{X}_{5}$ & 118 & 72 & 128 & 74 & 108 & 85 & 100 & 119 \\
\hline$X_{6}$ & 148 & 137 & 122 & 131 & 156 & 144 & 150 & 157 \\
\hline $\mathbf{X}_{7}$ & 124 & 94 & 79 & 88 & 72 & 101 & 114 & 137 \\
\hline $\mathbf{X}_{8}$ & 94 & 74 & 73 & 74 & 98 & 86 & 95 & 97 \\
\hline
\end{tabular}

All the entries are non-negative and it has no pure Nash Equilibrium. 
Table A2: Payoff Table for Vodag-Ghana

\begin{tabular}{|c|c|c|c|c|c|c|c|c|}
\hline VOBAG & $\mathbf{Y}_{9}$ & $Y_{10}$ & $Y_{11}$ & $Y_{12}$ & $Y_{13}$ & $Y_{14}$ & $Y_{15}$ & $Y_{16}$ \\
\hline $\mathbf{X}_{1}$ & 76 & 144 & 139 & 132 & 83 & 125 & 102 & 75 \\
\hline $\mathbf{X}_{2}$ & 74 & 138 & 137 & 128 & 85 & 111 & 102 & 78 \\
\hline $\mathbf{X}_{3}$ & 71 & 122 & 132 & 131 & 105 & 117 & 108 & 89 \\
\hline $\mathbf{X}_{4}$ & 88 & 135 & 133 & 137 & 98 & 122 & 103 & 89 \\
\hline $\mathbf{X}_{5}$ & 82 & 128 & 72 & 126 & 92 & 115 & 100 & 81 \\
\hline$X_{6}$ & 52 & 63 & 78 & 69 & 44 & 56 & 50 & 43 \\
\hline $\mathbf{X}_{7}$ & 76 & 106 & 121 & 112 & 128 & 99 & 86 & 63 \\
\hline $\mathbf{X}_{8}$ & 106 & 126 & 127 & 126 & 102 & 114 & 105 & 103 \\
\hline
\end{tabular}

All the entries are non-negative and it has no pure Nash Equilibrium.

\section{APPENDIX II}

A Sample Calculation Using Lemke-Howson Algorithm

Table A3: Bimatrix Payoff of Two-Player Game

\begin{tabular}{|l|l|l|l|}
\hline PT P2 & 4 & 5 & 6 \\
\hline 1 & 1,2 & 3,1 & 0,0 \\
\hline 2 & 0,1 & 0,3 & 2,1 \\
\hline 3 & 2,0 & 1,0 & 1,3 \\
\hline
\end{tabular}

In the payoff table, the entries are positive and there are no pure Nash Equilibria.

Step 1: Preprocessing

Table A4 Payoff Table for Player 1 (A)

\begin{tabular}{|l|l|l|l|}
\hline & $y_{4}$ & $y_{5}$ & $y_{6}$ \\
\hline$x_{1}$ & 1 & 3 & 0 \\
\hline$x_{2}$ & 0 & 0 & 2 \\
\hline$x_{3}$ & 2 & 1 & 1 \\
\hline
\end{tabular}

All the entries are non-negatives and there is no pure Nash Equilibrium.

$$
Z=\max \sum_{j=m+1}^{m+n} a_{i j} y_{j}, i=1,2, \cdots, m
$$


Subject to $A^{i} y \leq 1$, which are:

$$
\begin{aligned}
& y_{4}+3 y_{5}+0 y_{6} \leq 1 \\
& 0 y_{4}+0 y_{5}+2 y_{6} \leq 1 \\
& 2 y_{4}+y_{5}+y_{6} \leq 1 \\
& y_{4} \geq 0, y_{5} \geq 0, y_{6} \geq 0
\end{aligned}
$$

with strict inequality $y_{j}>0$ for payoff calculation.

Table A5: Payoff Matrix for Player 2 (B)

\begin{tabular}{|l|l|l|l|}
\hline & $y_{4}$ & $y_{5}$ & $y_{6}$ \\
\hline$x_{1}$ & 2 & 1 & 0 \\
\hline$x_{2}$ & 1 & 3 & 1 \\
\hline$x_{3}$ & 0 & 0 & 3 \\
\hline
\end{tabular}

All the entries are non-negatives and there is no pure Nash Equilibrium.

$$
\operatorname{Max} W=\max \sum_{i=1}^{m} x_{i}^{T} b_{i j}, j=m+1, m+2, \cdots, m+n .
$$

Subject to $\boldsymbol{x}^{T} \boldsymbol{B}_{j} \leq 1$, which are:

$$
\begin{array}{cc}
2 x_{1}+x_{2}+0 x_{3} \leq 1 & {[B 1]} \\
x_{1}+3 x_{2}+0 x_{3} \leq 1 & {[B 2]} \\
0 x_{1}+x_{2}+3 x_{3} \leq 1 & {[B 3]} \\
x_{1} \geq 0, x_{2} \geq 0, x_{3} \geq 0 &
\end{array}
$$

with strict inequality $x_{i}>0$ for payoff calculation.

Adding slack variable $\boldsymbol{r}_{\boldsymbol{i}}$ to $[\boldsymbol{A}]$ convert the system to equalities:

$$
\begin{aligned}
& y_{4}+3 y_{5}+0 y_{6}+r_{1}=1 \\
& 0 y_{4}+0 y_{5}+2 y_{6}+r_{2}=1 \\
& 2 y_{4}+y_{5}+y_{6}+r_{3}=1
\end{aligned}
$$

Adding the slack variable $\boldsymbol{S}_{\boldsymbol{i}}$ to $[\boldsymbol{B}]$ convert the system to equalities:

$$
\begin{aligned}
& 2 x_{1}+x_{2}+0 x_{2}+s_{4}=1 \\
& x_{1}+3 x_{2}+0 x_{2}+s_{5}=1 \\
& 0 x_{1}+x_{2}+3 x_{2}+s_{6}=1
\end{aligned}
$$


Step 2: The Initial Tableaux

The Initial Tableaux are $r=1-A y$

$$
\begin{aligned}
& r_{1}=1-y_{4}-3 y_{5} \\
& r_{2}=1 \quad-2 y_{6} \\
& r_{3}=1-2 y_{4}-y_{5}-y_{6}
\end{aligned}
$$

and $s=1-B^{T} x$,

$$
\begin{aligned}
& s_{4}=1-2 x_{1}-x_{2} \\
& s_{5}=1-x_{1}-3 x_{2} \\
& s_{6}=1-x_{2}-3 x_{3}
\end{aligned}
$$

Step 3: Pivoting

We then arbitrarily choose some $x$ or $y$ variable to bring in to the basis, corresponding to the arbitrary choice $k_{0}$ of label that we remove. Let's bring $x_{l}$ in. By considering the min-ratio rule (i.e. looking at the coefficients of $x_{l}$ in the $[\boldsymbol{B}]$ tableau) it is $s_{4}$ that must leave the basis. Therefore, we solve $[\boldsymbol{B} 1]$ for $x_{1}$, obtaining a new equation $\left[\boldsymbol{B}^{\prime} \mathbf{1}\right]$, and then substitute the new equation into $[\boldsymbol{B} 2]$ and $[\boldsymbol{B} 3]$ obtaining:

$$
\begin{aligned}
& x_{1}=1 / 2-1 / 2 s_{4}-1 / 2 x_{2} \\
& s_{5}=1 / 2+1 / 2 s_{4}-5 / 2 x_{2} \\
& s_{6}=1-x_{2}-3 x_{3}
\end{aligned}
$$

The main feature of the Lemke-Howson Algorithm is that the variable, which just left the basis, determines the variable to enter the basis next.

There are $\boldsymbol{m} \times \boldsymbol{n}$ complementary pairs of variables: $\left\{\boldsymbol{r}_{\boldsymbol{i}}, \boldsymbol{x}_{\boldsymbol{i}}\right\}$ for $\boldsymbol{i} \in \boldsymbol{M}$ and $\left\{s_{j}, y_{j}\right\}$ for $j \in N$.

Since $s_{4}$ just left the basis, $y_{4}$ is brought in. Examining the $[A]$ tableau we realized that $r_{3}$ is the winner of the minratio, and is therefore leaves the basis. We obtain the following as a result:

$$
\begin{array}{rr}
r_{1}=1 / 2+1 / 2 r_{3}-5 / 2 y_{5}+1 / 2 y_{6} \\
r_{2}=1 & -2 y_{6} \\
y_{4}=1 / 2-1 / 2 r_{3}-1 / 2 y_{5}-1 / 2 y_{6}
\end{array}
$$


Since $\boldsymbol{r}_{3}$ left, now $\boldsymbol{x}_{3}$ enters the other tableau, and by the min-ratio rule $\boldsymbol{S}_{6}$ leaves.

$$
\begin{aligned}
& x_{1}=1 / 2-1 / 2 s_{4}-1 / 2 x_{2} \\
& s_{5}=1 / 2+1 / 2 s_{4}-5 / 2 x_{2} \\
& x_{3}=1 / 3 \quad-1 / 3 x_{2}-1 / 3 s_{6}
\end{aligned}
$$

Since $\boldsymbol{s}_{6}$ left, now $\boldsymbol{y}_{6}$ enters, and by the min-ratio rule $\boldsymbol{r}_{2}$ leaves.

$$
\begin{aligned}
& r_{1}=3 / 4+1 / 2 r_{3}-5 / 2 y_{5}-1 / 4 r_{2} \\
& y_{6}=1 / 2-1 / 2 r_{2} \\
& y_{4}=1 / 4-1 / 2 r_{3}-1 / 2 y_{5}+1 / 4 r_{2}
\end{aligned}
$$

Since $\boldsymbol{r}_{2}$ left, now $\boldsymbol{x}_{2}$ enters, and the min-ratio rule $\boldsymbol{s}_{5}$ leaves.

$$
\begin{aligned}
& x_{1}=2 / 5-3 / 5 s_{4}+1 / 5 s_{5} \\
& x_{2}=1 / 5+1 / 5 s_{4}-2 / 5 s_{5} \\
& x_{3}=4 / 15-1 / 15 s_{4}+2 / 15 s_{5}-1 / 3 s_{6}
\end{aligned}
$$

Since $\boldsymbol{S}_{5}$ left, now $\boldsymbol{y}_{5}$ enters, and by the min-ratio rule $\boldsymbol{r}_{1}$ leaves.

$$
\begin{aligned}
& y_{5}=3 / 10+1 / 5 r_{3}-2 / 5 r_{1}-1 / 10 r_{2} \\
& y_{6}=1 / 2 \quad-1 / 2 r_{2} \\
& y_{4}=1 / 10-3 / 5 r_{3}+1 / 5 r_{1}+3 / 10 r_{2}
\end{aligned}
$$

\section{Step 4: Output}

Since $\boldsymbol{x}_{1}$ was the initial variable to enter the basis, and $\boldsymbol{r}_{1}$ just left, the complementarity conditions are satisfied. That is, if $\boldsymbol{x}_{\boldsymbol{i}}$ was the variable to enter, we stop when $\boldsymbol{X}_{\boldsymbol{i}}$ or its complement leaves.

In a tableau we obtain values for the basic variables by setting the non-basic variables to zero. Hence the variables values are:

$$
r=(0,0,0), s=(0,0,0), x=(2 / 5,1 / 5,4 / 15), y=(1 / 10,3 / 10,1 / 2) .
$$

The results above were normalized to obtain Nash Equilibrium as:

$$
(\operatorname{normalised}(x), \text { normalised }(y))=((6 / 13,3 / 13,4 / 13),(1 / 9,3 / 9,5 / 9))
$$

